\title{
Hydrostatic Pressure Project: Linked-Class Problem-Based Learning In Engineering
} Freddie J. Davis, Ph.D., West Texas A\&M University, USA

Pamela Lockwood-Cooke, Ph.D., West Texas A\&M University, USA

Emily M. Hunt, Ph.D., West Texas A\&M University, USA

\begin{abstract}
Over the last few years, WTAMU Mathematics, Engineering and Science faculty has used interdisciplinary projects as the basis for implementation of a linked-class approach to ProblemBased Learning (PBL). A project that has significant relevance to engineering statics, fluid mechanics, and calculus is the Hydrostatic Pressure Project. This project was developed by faculty associated with the NSF-funded INCRSE project, Increasing Numbers and Connections in Science, Math, and Engineering, for application of the linked-class PBL to calculus II and engineering statics. The students in the linked classes were to predict the horizontal force and the vertical force on a submerged surface and determine the appropriate locations of these forces in order to experimentally verify the calculations. They worked in groups to outline their procedures, develop their functional relations, record experimental data, and report on their findings. Assessment efforts have focused on student laboratory reports and student perceptions about their learning and experiences with this linked-class PBL project collected through surveys and focus groups. In all the surveys and focus groups conducted with students who had participated in the Hydrostatic Pressure Project, all of the students felt their experience was beneficial and had enhanced their understanding and applications of engineering and mathematics.
\end{abstract}

Keywords: problem-based learning; engineering education; undergraduate project

\section{INTRODUCTION}

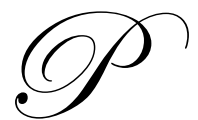

roblem-Based Learning (PBL) is a problem-centered teaching method with exciting potential in engineering education for motivating and enhancing student learning and is possibly the most important and powerful pedagogical innovation in history [1-5]. PBL has become increasingly popular in K-12 and higher education worldwide since it was first introduced in medical education in the late 1960's [1]. However, it has not gained significant popularity in engineering curricula due to the large time-scale needed to solve complex engineering problems and the difficulties associated with assessment of its impact on students. Previous work by the authors examines a new method for incorporating PBL into undergraduate engineering curricula through a linked-class approach involving math and physics courses as well as engineering courses [4-7]. Studies indicate that the application and integration of foundation disciplines such as mathematics and physics into practical engineering applications increases student engagement in the learning process [2-7]. Development of strategies for successful implementation of PBL in engineering curricula is very important to engineering education because of the potential positive impact on student learning.

Implementation of PBL in engineering education has the potential to bridge the gap between theory and practice. Two common problems are encountered when attempting to integrate PBL into the undergraduate engineering classroom: 1) the large time requirement to complete a significant, useful problem and 2) the ability to determine its impact on students. Engineering, mathematics, and science professors at West Texas A\&M University (WTAMU) have worked to overcome the large time commitment associated with implementation of PBL in a single 
course by integrating small components of the larger project into each of their classes and then linking these components with a culminating experience. This linked-class PBL experience addresses course concepts, reinforces connections among the courses, and provides real-world applications for the students. Assessment of linked-class PBL in the form of student focus groups and surveys indicates students view the experience as beneficial, increasing their understanding of content and applications in each discipline. More details about implementation of the linkedclass method for PBL, an example PBL project, and how difficulties in evaluation of the linked-class PBL experiences are being addressed are available in [1].

Over the last few years, WTAMU faculty has used various projects as the basis for their implementation of the linked-class approach to PBL in engineering, mathematics, and physics classes [1]. A new project that has significant relevance to engineering statics, fluid mechanics, and calculus is the Hydrostatic Pressure Project. The project was created from the course objectives of both calculus II and engineering statics, and provides first-year engineering students with a significant application of the material from both courses. All 30 students participating in this project were sophomore mechanical engineering majors concurrently enrolled in calculus II and engineering statics. The following sections of this paper examine (1) a linked-class PBL project utilized in engineering statics and calculus II; and (2) efforts to assess the impact of the Hydrostatic Pressure Project.

\section{LINKED-CLASS HYDROSTATIC PRESSURE PROJECT}

The design of many engineering systems such as water dams and liquid storage tanks requires the determination of the forces acting on the surfaces using fluid statics. The complete description of the resultant hydrostatic force acting on a submerged surface requires the determination of the magnitude, direction, and the line of action of the force, or the horizontal and vertical components of the force [8]. Because the local pressure of a fluid is a function of the fluid density and depth at a given point, calculus allows the engineer to determine the total force on the submerged surface by proper integration of the local product of pressure and area. Calculus also provides tools by which the engineer may determine the point of action of the total force and thereby determine if there is any moment or bending considerations that must be addressed. This is a prime example of the interdependence of engineering and mathematics and thus, a perfect problem for use in this linked-class PBL project.

The calculus II and statics instructors worked prior to the semester to synchronize the schedule of activities in both courses to coordinate the timing of the mathematics and engineering content relevant to the project. The applications of integration content of calculus II may be covered at various times in the course, beginning, midterm, or at the conclusion. For purposes of this project it was determined that the midterm would allow for both course to cover the content relevant to the project at approximately the same time. It was critical that the faculty did this initially. The faculty also contacted each other weekly to assure that the courses were on schedule. On the few occasions when one course fell temporarily behind schedule, the other instructor was informed immediately to maintain the course coordination. Each faculty member occasionally visited the other classroom to maintain a consistent atmosphere of a learning community with coordination between the curriculum and the instructors.

\section{Theoretical Component}

In this project, the students were placed in groups assigned by the instructors. The students were to use calculus to predict the horizontal force and the vertical force on a given submerged surface and to determine the appropriate location of the horizontal force and vertical force. Constant slope and quarter-cylinder surfaces were included in both the experimental and theoretical portion of the experiment. The students were given two depths of interest for each surface type: half way up the surface; to the top of the surface. The surface in questions will be the leading surface of a wedge, with the wedge incline being the constant slope or quarter-cylinder as shown in Figure 1. For the quarter-cylinder, the slope was replaced with a concave arc of constant radius equal to the height of the block. 
A.

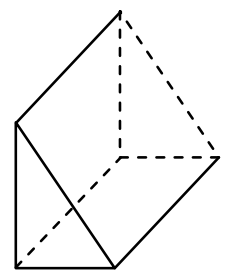

B.

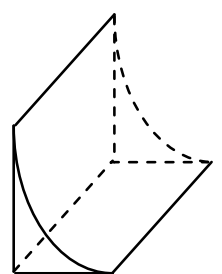

Figure 1: Leading Surface Of Wedge A. Constant-Slope; B. Quarter-Cylinder

\section{Experimental Component}

Wooden blocks were constructed with leading surfaces described previously and were placed into a small aquarium so that the fluid may be introduced to the surface. The left and bottom surfaces of the wedge (Fig. 2) will rest against the bottom and side of the aquarium. Load cells will be placed between the wedge and the surface of the aquarium to measure the horizontal and vertical forces on the submerged surface. The water will be filled into a bladder that will adapt its shape to that of the aquarium walls and the wedge without seeping between the walls and the wedge.

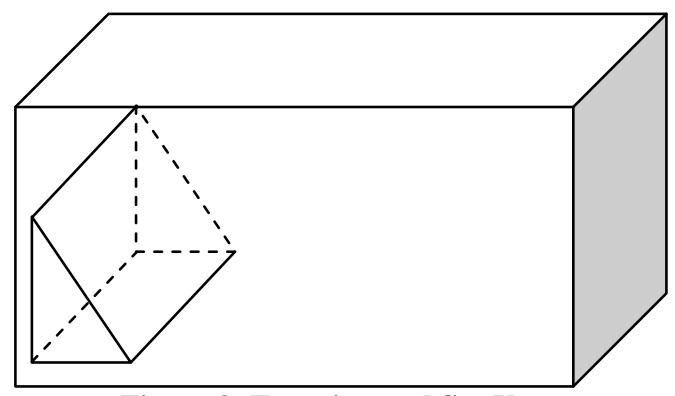

Figure 2: Experimental Set-Up

To experimentally verify the calculated force, the students used low profile load cells placed directly below the wedge and (relative to the above drawing) to the left of the wedge. The load cells to be used were about three inches by one inch. However, the sensitive area of the load cell was an elevated 'button' which is only one-half inch in diameter. The students were to take the necessary measurements to calculate the functional relations required for the centroid and force calculations. The students were then to calculate where the load cell must be placed for the surface geometry and fluid level and then elevate the fluid level to the appropriate depth. The following tables were given in the class handout to help guide the students in the experiments.

Table 1. Constant Slope (Populated With Example Student Data, Units Are Inches And lbf)

\begin{tabular}{|l|c|c|c|c|c|c|}
\hline Water Depth & $\begin{array}{c}\text { Calculated } \\
\text { Horizontal } \\
\text { Force }\end{array}$ & $\begin{array}{c}\text { Calculated } \\
\text { Vertical Force }\end{array}$ & $\begin{array}{c}\text { Calculated } \\
\text { Horizontal } \\
\text { Centroid }\end{array}$ & $\begin{array}{c}\text { Calculated } \\
\text { Vertical } \\
\text { Centroid }\end{array}$ & $\begin{array}{c}\text { Measured } \\
\text { Horizontal } \\
\text { Force }\end{array}$ & $\begin{array}{c}\text { Measured } \\
\text { Vertical Force }\end{array}$ \\
\hline Half & 3.46 & 1.3 & 0.2 & 0.5 & 3.08 & 2.69 \\
\hline Full & & & & & & \\
\hline
\end{tabular}


Table 2: Quarter-Cylinder (Populated With Example Student Data, Units Are Inches And lbf)

\begin{tabular}{|c|c|c|c|c|c|c|}
\hline Water Depth & $\begin{array}{c}\text { Calculated } \\
\text { Horizontal } \\
\text { Force }\end{array}$ & $\begin{array}{c}\text { Calculated } \\
\text { Vertical Force }\end{array}$ & $\begin{array}{c}\text { Calculated } \\
\text { Horizontal } \\
\text { Centroid }\end{array}$ & $\begin{array}{c}\text { Calculated } \\
\text { Vertical } \\
\text { Centroid }\end{array}$ & $\begin{array}{c}\text { Measured } \\
\text { Horizontal } \\
\text { Force }\end{array}$ & $\begin{array}{c}\text { Measured } \\
\text { Vertical Force }\end{array}$ \\
\hline Half & 3.58 & 1.04 & 0.2 & 0.5 & 1.15 & 0.38 \\
\hline Full & 3.21 & 4.01 & 0.1 & & & \\
\hline
\end{tabular}

The students were given approximately two class hours in engineering statics and in calculus II to take the measurements and complete the calculations. All other group work was to be conducted out of class. Each group was then responsible for analyzing the results and comparing them to their calculated horizontal and vertical forces. A final, formal engineering report was then required from each group that included the work performed in the calculus and engineering classes and the final results.

\section{Engineering Statics}

Before this project was introduced to the class, the students were taught problem-solving skills that included basic statics topics such as: particle statics (i.e. forces in a plane and in space), rigid bodies or equivalent systems of forces, equilibrium of rigid bodies, and distributed forces, centroids, and centers of gravity. In Engineering Statics, the students learned how the determination of the centroid of an area simplifies the analysis of beams subjected to distributed loads and the computation of the forces exerted on submerged rectangular surfaces, such as hydraulic gates and portions of dams [8-9].

This project gave the undergraduate engineering students an opportunity to test and experimentally validate their calculations from calculus II. If the load cells were not correctly placed along the line of the horizontal and vertical forces, the load cells would rotate and no experimental verification could be made. If the load cells were correctly placed, then the force could be accurately measured.

\section{Calculus II}

The calculus II class at the time of the project had worked on techniques of integration and was beginning applications of integration which include area between two curves, volumes and surface areas of revolution, length of curve, center of mass, work, and pressure generated by a fluid against a submerged surface. Center of mass, and fluid pressure force against a surface are difficult topics to teach in a lecture class setting and students have trouble visualizing both center of mass and the concept of a distributed pressure force. In addition, these topics are introduced in calculus II with the goal of teaching the students a modeling technique that can be generalized in many different applications. Calculus II faculty enjoyed this project because it integrated all of these topics with application of engineering principles and yet not being precisely like the contexts of the problems in calculus assessed the students' ability to generalize and elaborate on what they had learned. Before the students were given the Hydrostatic Pressure Project in calculus II, they worked the following problems (Figs. 3 and 4) in class that required the application of integration principles to solve for pressure force on a submerged surface.

The accompanying figure shows a rectangular swimming pool whose bottom is an inclined plane. Find the fluid force on the bottom when the pool is filled to the top. 


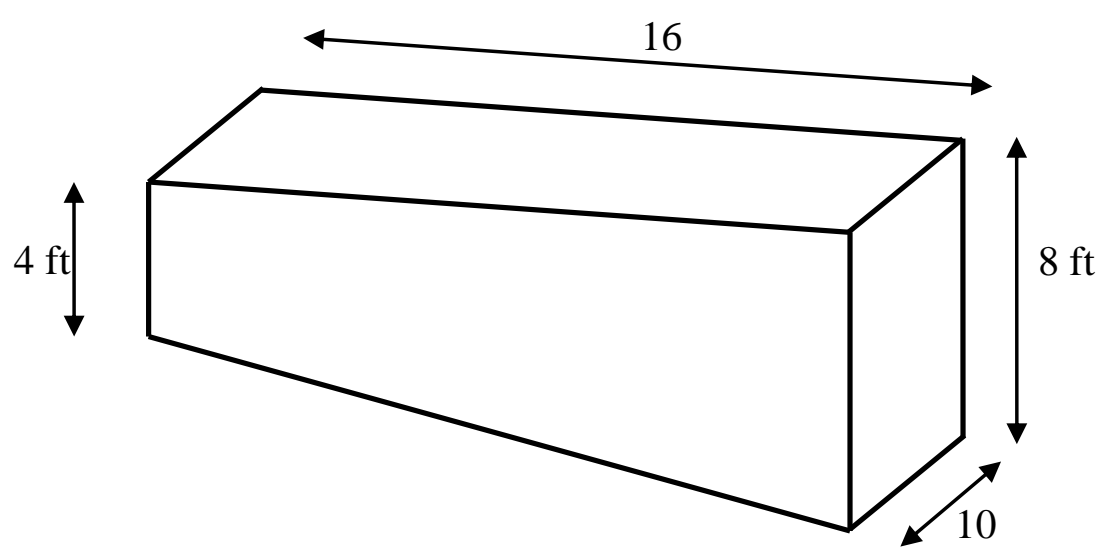

Figure 3: First Example Problem Worked In Calculus II To Solve For Fluid Force [10]

The accompanying figure shows a dam whose face is an inclined rectangle. Find the fluid force on the face when the water level is even with the top of this dam.

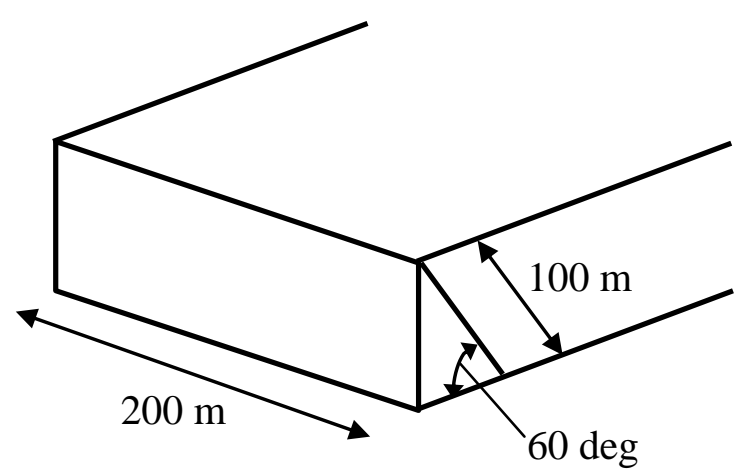

Figure 4: Second Example Problem Worked In Calculus II To Solve For Fluid Force [10]

Working on these problems in class prior to the project gave the students in the linked classes the experience to approach the Hydrostatic Pressure Project with confidence and a relatively sound plan.

\section{ASSESSMENT OF LINKED PROJECT}

The initial assessment of the Hydrostatic Pressure project was provided by the student formal engineering reports. Prior course content in both calculus II and engineering statics provided students with the necessary principles and the PBL project gave the students an opportunity to apply the concepts to a new situation, assessing their knowledge of the previous material as well as the students' ability to adapt the content to a new situation. Both instructors provided opportunities in their classes for open student discussions of the problem, but provided little assistance. All groups successfully completed the measurements required to find the functional relationships that described the submerged surface. All groups were able to define the surface relationships although some used numerical techniques and others theoretical. All groups were able to find the centroid from their calculations.

The students showed growth not only in their understanding of the theoretical part of the project, but also in their ability to design and conduct experiments. The students experienced problems with the experimental set-up in 
that they could not get the blocks of wood to sit flush with the aquarium when the load sensors were placed on them. The students calculated the centroids theoretically and then placed the load sensors at those specific places and adjustments had to be made because of the physical properties of the block. This caused a shift in the block and resulted in a false load reading on the meter. The students had to work as a team to adjust the placement of the cells and water against the surface until they could get an accurate reading. The groups also learned about buoyancy in a very real and physical way. Because the only previous experience that the students have with submerged objects was examples from the book, they did not take into account the weight of the block in their original calculations. Several groups had to go back and refigure the location of the centroid after already beginning their experimentation.

Since this implementation of the linked-class PBL Hydrostatic Pressure Project was part of the INCRSE project, evaluation of the PBL experiences was initially included with the external evaluation services provided INCRSE by the West Texas Office of Evaluation and Research (WTER). These evaluation efforts have focused on student perceptions about their experiences and learning gains with PBL collected through student surveys and student focus groups. WTER used the Student Assessment of Learning Gains (SALG) instrument as the model for developing survey questions related to the evaluation of the linked-class PBL. SALG instruments ask students to comment on their own learning and how different aspects of a class contributed to their learning. Survey questions were developed using the model instruments presented on the Student Assessment of Their Learning Gains (SALG) website (originally www.wcer.wisc.edu/salgains/instructor but www.salgsite.org as of June 30, 2008) [11]. The original SALG instrument was developed by Elaine Seymour in 1997 while she was co-evaluator for two National Science Foundation-funded chemistry consortia. It was revised by Stephen Carroll, Elaine Seymour, and Tim Weston in 2007. This instrument gathers student perspectives about the degree to which a course has impacted their learning and understanding. The SALG is a good instrument to use for evaluation of this project since PBL focuses more on learning to learn and less on a particular body of knowledge. The National Science Foundation Education Standards propose several assessment standards that can be used in designing PBL assessments [12]. One of these is to provide students the opportunity to evaluate and reflect on their own understanding. This is a key element in PBL and allows the students to compare their performance with their personal goals and to monitor their own learning. This can be accomplished through surveys, focus groups, and personal interviews with the students. According to Waters and McCraken [13], the ability of the PBL to foster reflection in students is dependent on the assessment tool used which can overcome the deficiencies of any particular facilitator in fostering reflection. An effective assessment tool will provide a fair and objective report of student progress.

In all the surveys and focus groups conducted with students who had participated in a linked-class PBL experience, all of the students felt their experience was beneficial and had enhanced their understanding and applications of engineering and mathematics. They also indicated a desire to participate in other PBL projects and experiences. Specific feedback received from the SALG instrument and the focus groups is listed below.

Question: What was most valuable to you about the project in calculus II and statics?

\section{Response:}

- $\quad$ It helped link calculus and engineering

- $\quad$ They fit with each other, and they pushed you to your limits

- The reinforcement of the concepts learned in class

- $\quad$ Learning how to use calculus on engineering problems

- $\quad$ Working with other students and learning from them 
Question: How could the project in calculus II and statics be improved?

Response:

- $\quad$ More time available to work on projects

- $\quad$ More communication with professor

- Better explanation on how to complete them

- Don't assign in the last few weeks of school

- $\quad$ Have more projects like this

Overall, assessment of students and professors involved in the Hydrostatic Pressure Project indicates that this was an effective way to teach students to calculate the hydrostatic force on a submerged surface.

\section{CONCLUSIONS}

The study of centroids and horizontal and vertical components of forces acting on a submerged surface is important not only in Engineering Statics, but also to prepare students for Fluid Mechanics. Students indicated their desire to advance to Fluid Mechanics after participating in the Hydrostatic Pressure project. This is a very valuable, hands-on experience for both engineering and mathematics students. This project provided an experiential learning situation for them that reinforced concepts in dimensional analysis, problem solving, critical thinking, group work, and communication.

\section{AUTHOR INFORMATION}

Dr. Freddie Davis is an associate professor of nuclear engineering at West Texas A\&M University. He currently serves as the Department Chair for Engineering and Computer Science.

Dr. Pamela Lockwood-Cooke is an associate professor of mathematics at West Texas A\&M University. She is the principal investigator of the National Science Foundation Science Talent Expansion Program Increasing Numbers, Connections, and Retention in Science and Engineering (INCRSE).

Dr. Emily M. Hunt is an associate professor of mechanical engineering at West Texas A\&M University. Her research focus is creating energetic and explosive nanomaterials through combustion synthesis. She has been studying K-12 and undergraduate engineering education for the last several years.

\section{REFERENCES}

1. Hunt E.M., Lockwood P., Kelley, J. Linked-Class Problem-Based Learning in Engineering: Method and Evaluation, American Journal of Engineering Education, 2010.

2. Perrenet, J.C., Bouhuijis, P.A., and Smits, J.G.M.M. The Suitability of Problem-based Learning for Engineering Education: theory and practice, Teaching in Higher Education 5 (33) (2000) 345-358.

3. Costa, L.R.J., Honkala, M., and Lehtovuori, A. Applying problem-based learning approach to teach elementary circuit analysis, IEEE Transactions on Education 50 (1) (2007) 41-48.

4. Woods, D.R., Problem-based learning for large classes in Chemical Engineering, Bringing Problem-based learning to Higher Education: theory and practice, (1996) 91-99.

5. Eugene, Christian. How to each at the university level through an active learning approach: Consequences for teaching basic electrical measurements, Measurement 39 (2006) 936-946.

6. Cawley, P. A Problem-based Module in Mechanical Engineering, The Challenge of Problem Based Learning, (1991) 177-185.

7. Perrenet, J.C. and Wolters, M.A.D., The art of checking: a case study of students erroneous behaviour in introductory Algebra, Journal for Mathematical Behaviour 13 (1994) 335-358.

8. Cimbala J.M. and Cengel Y.A., Essentials of Fluid Mechanics: Fundamentals and Applications, McGraw Hill, 2008. 
9. Beer F.P., Johnston E.R., and Eisenberg E.R., Vector Mechanics for Engineers: Statics, Eight Edition, McGraw Hill, 2007.

10. Anton, H., Bivens, I., and Davis S., Calculus Early Transcendental, $9^{\text {th }}$ edition, John Wiley and Sons, 2009.

11. Seymour, E. Student Assessment of Learning Gains website originally www.wcer.wisc.edu/salgains/instructor but www.salgsite.org as of June 30, 2008.

12. National Science Education Standards, Assessments in Science Education, National Academy Press, 1994.

13. Waters, R. and McCraken, M., Assessment and Evaluation in Problem Based Learning. Georgia Institute of Technology. 